\title{
The Relationship between Teachers and Students from the Perspective of Geography*
}

\author{
LiChunlan $^{1}$, GuanQige ${ }^{2}$, Haobisigalatu ${ }^{2}$, ZhangJiquan ${ }^{3}$, YinShan $^{1}$, HuRicha $^{1}$ and WangRuixia ${ }^{4}$ \\ ${ }^{1)}$ College of Geographical Sciences Normal University in Inner Mongolia, Hohhot 010022, China; \\ ${ }^{2)}$ Mongolia nationality middle school in Inner Mongolia Autonomous Region, Xilinhaote City ,026000, China3Remote Sensing and \\ Information Key Laboratory, Inner Mongolia Normal University, Hohhot 010022, China; \\ ${ }^{3)}$ College of Environment Northeast Normal University, Changchun, 130024, China; \\ ${ }^{4)}$ Bayannaoer Tin Ka Ping foreign language school, Bayannaoer City, 015000, China
}

\begin{abstract}
On the geography teachers and students from the perspective of relationship were studied, the previous studies on the relationship between teachers and students lack of empirical and practical. This paper adopts empirical research method of questionnaire investigation and literature collection, research status of the relationship between teachers and students from the perspective of the current geography learning level students from different angle, and the establishment of different levels of study of teacher-student relationship provides useful suggestions.
\end{abstract}

Keywords - Geographical perspective, the relationship between teachers and students, Teacher, Middle school student, College student, Graduate student

\section{地理视角下的师生关系}

\author{
李春兰 $^{1} \quad$ 关其格 $^{2}$ 浩必斯嘎拉图 ${ }^{2}$ 张继权 $^{3}$ 银山 $^{1}$ 胡日查 $^{1}$ 王瑞霞 $^{4}$ \\ 1) 内蒙古师范大学地理科学学院,呼和浩特市,010022; \\ 2) 内蒙古自治区蒙古中学,锡林浩特市, $026000 ;$ \\ 3) 东北师范大学环境学院,长春,130024; \\ 4) 巴彦淖尔市田家炳外国语学校,巴彦淖尔市,015000
}

摘 要: 对地理视角下的师生关系进行了研究, 以往有关师生关系的研究缺乏实证性和可操作性。本文采用问卷调查和文献收集 等实证研究方法, 从不同学习层次的学生角度对当前地理视角下师生关系的现状进行研究, 并针对不同学习层次的师生关系的建立提 供了可取的建议。

关键字：地理视角, 师生关系, 教师, 中学生, 大学生, 研究生

\section{1. 中学的师生关系研究}

\section{1 中学地理师生关系的基本要求}

《中学教师专业标准》的基本理念明确了, 学生的职 责，老师的职责，由此可以更好的维持师生关系。基本理 念如下: 1. 学生为本。尊重中学生权益, 以中学生为主体, 充分调动和发挥中学生的主动性; 遵循中学生身心发展特
点和教育教学规律, 提供适合的教育, 促进中学生生动活 泼学习、健康快乐成长, 全面而有个性的发展。2. 师德 为先。热爱中学教育事业, 具有职业理想, 践行社会主义 核心价值体系, 履行教师职业道德规范。关爱中学生, 尊 重中学生人格, 富有爱心、责任心、耐心和细心; 为人师 表, 教书育人, 自尊自律, 以人格魅力和学识魅力教育感 染中学生, 做中学生健康成长的指导者和引路人。3. 能

\footnotetext{
* Inner mongolia normal university graduate students' research \& Innovation fund (NO. CXJJSZD13005) and Inner Mongolia Autonomous Region graduate education innovation project.
} 
力为重。把学科知识、教育理论与教育实践相结合, 突出 教书育人实践能力; 研究中学生, 遵循中学生成长规律, 提升教育教学专业化水平; 坚持实践、反思、再实践、再 反思, 不断提高专业能力。 4 . 终身学习。学习先进中学 教育理论, 了解国内外中学教育改革与发展的经验和做法; 优化知识结构, 提高文化素养; 具有终身学习与持续发展 的意识和能力, 做终身学习的典范。

\section{2 中学地理教学中的师生关系的现状分析}

中学地理教学中的师生关系的现状又是如何的呢? 是 不是都是朝着民主型的方向发展呢, 调查发现存在这样一 些问题：第一，传统观念的束缚。我们在对老师和学生的 访谈中发现， “师道尊严” 的传统思想在一些教师中仍然 存在, 特别是在年龄稍大些的教师中, 更为明显。部分教师 缺乏管理艺术, 以管代教和以批评代替教育的做法挫伤了 学生的自尊心, 使得他们的行为得不到理解, 拉大了师生间 的距离, 并造成学生的自闭心理和逆反心理。第二, 学生与 教师情感的冲突。初中生的身心在迅速发展, 他们有很多的 困惑与苦恼, 大部分学生都比较向往和教师进行感情上的 沟通调查中有的学生希望老师能像朋友一样和他们谈心。 而老师们却反映, 目前使用的新教材比较灵活, 要求教师 的知识面要非常广, 因此, 老师把大部分精力花费在备课方 面, 很少有时间与学生进行情感沟通。第三, 评价体系的滞 后。在访谈中许多老师反映, 评价体系是目前面临的最大的 问题, 用了新教材, 却用老一套的方式评价学校、老师和学 生, 这极大地伤害了老师和学生的积极性, 从而进一步影响 到师生关系。中考的指挥棒没有变, 在教学成绩这座大山的 重压下, 教师和学生都为 “分儿” 疲于奔命, 使得学生的全 面发展和个人潜能被忽视, 造成师生关系疏远。第四, 课程 资源严重缺乏。在访谈中老师们反映, 由于学校师资力量不 足, 一般都是大班授课, 班级人数太多, 老师无法顾及每个 学生, 互动式课堂教学难以开展。老师对学生的了解和帮助 不够, 学生就容易对老师产生不满情绪。

\section{3 中学地理师生关系的构建}

有了确立师生关系的理论基础, 下面以具体事例阐明 在教学过程中老师和学生应该建立什么样的师生关系。以 人教版义务教育课程标准实验教科书地理为例, 该书突出 了 “以学生为中心, 以学生的发展为本” 的教育思想, 充 分体现了人文性、探究性、实践性、情感性等特点。要求 师生在平等、互动、和谐中学习知识、掌握方法和增强技 能。构建新型师生关系是顺利实施新教材教学的关键。

(1) 新教材强调在教学过程中应建立平等、和谐的师生关系
新教材突出了 “人文性” 特点。要求教师尊重学生的 个性发展, 尊重学生的人格, 学生体验到自己作为人的一 种尊严感和幸福感。教学过程中要树立平等、和谐的师生 关系。首先教师要对学生一视同仁, 要把学生看成与自己 有着平等关系的公民, 爱 “金凤凰” 也爱 “丑小鸭”。不 管他们的经济地位和社会背景如何, 不管他们学习成绩如 何, 坚决不歧视 “差生”, 让学生在平等、尊重的氛围中 得到尊重, 同时也学会尊重他人。二是教师要敢于在学生 面前承认自己偶尔的失误, 让学生感到教师的坦诚和求实 精神, 这种人格魅力会对学生产生潜移默化的作用。教师 应通过尊重、赏识、关爱等, 把学生放在做 “人” 的主体 地位上, 牢固树立 “以生为本” 的教育思想, 积极倡导和 实践 “尊重教育”、“赞赏教育”。

（2）新教材强调学习方式的探究性一一师生互动、合作

新教材要求: 改变过去以教师为中心, 课堂为中心和 书本为中心的局面, 改变传统的讲授型、灌输型的教学模 式, 本人比较赞同内蒙古师范大学苏宝芳教授的 “双动两 案” 教学模式, 是指在建构主义学习理论、元认知理论、 地理学习理论和地理教学理论等理论的指导下建立起来 的, 以学生的地理学习方案 (以下简称学案) 与教师的地 理教学设计方案 (以下简称教案) 为媒介, 以学生学习活 动、教师教学活动为手段, 以提高学生地理学习能力、培 养学生地理素养, 提高地理教师教学能力为目标, 完整的 地理学习过程和教学过程有机结合的教学策略体系。地理 学案是由 “学习目标、自主学习、学会学习、课堂练习和 学 习小结” 等五部分组成, 地理教案是由 “课题名称、课标 标准及其解读、教材分析、学情分析、设计思想、教学目 标、重点和难点、教学模式、教学 方法及教学媒体、教学 过程、课外探究、板书设计、学案作业题的答案要点、教 学反思、教学资源拓展” 等组成。

（3）新教材强调学习过程的实践性一一教师是引领者

地理是一门以观察实践为基础的自然科学, 与科技、 生活和社会有着密切的关系。新教材强调了在实践中培养 学生的科学探究能力和学习新知识的方法。教师要帮助学 生学会运用观察、实验、调查等方法广泛获取信息, 要从 学生的学习兴趣、生活经验出发, 引导学生结合日常现象 和身边的地理学习地理; 地理实验包括演示实验尽量由学 生自己探究实验, 倡导体验、实践、参与、合作与交流的 学习方式。教师角色应从知识的传授者转变为学生学习的 组织者、引领者和促进者。为使学生学有所得、学有所爱、 学有所思、学有所长, 教师要当好学生的引路人。

（4）新教材注重教育的情感性一一教师是激励者 
新教材不仅强调知识、能力目标, 而且注重情感目标。 要求教师在教学过程中有意识地以积极的情感去感染学 生、激励学生, 在地理教学中渗透情感、尊重、信任、友 善、理解、宽容、激励、亲情与友爱; 鞭策、鼓舞、感化、 召唤, 得到指导和建议, 形成积极的、丰富的人生态度与 情感体验。教师要拥有一颗爱心, 以情唤情, 要注重师生 情感交流, 达成默契。在地理教学中, 可采取: 展示地理 之美, 以美融情; 优化课堂提问, 以疑导情; 贴近社会生 活, 以用激情; 挖掘地理史实, 以史渗情等方法。平时教 学用语, 教师尽可把祝福、问候、关切、激励、真诚、信 任之情化作甘甜的泉水, 去滋润学生的心田, 引起师生教 与学的共鸣, 达到教与学两者的和谐与统一, 让师生在教 与学中达到认知与情感交融的最高境界, 使地理教学成为 心灵净化、陶冶情操、视觉满足和精神愉悦的活动体验; 让学生在 “快乐---兴趣” 的情绪状况下, 积极主动地学 习, 使学生从 “要我学” 升华为 “我要学”, 变 “苦学” 为 “乐学”, 从而达到以情感激发学生的求知欲望, 更好 地实现教学目标。新教材实施迫切要求构建新型的师生关 系。良好的师生关系是提高教学效率的保证, 更是实施素 质教育的保障。

\section{2. 大学的师生关系的现状}

本人参考了郭小英 “近十年来高校师生关系现状研究 综述” 中对近十年来高校师生关系存在的问题的研究的梳 理, 发现其问题主要表现在师生交往接触少、沟通减少、 师生关系存在功利倾向、师生感情淡漠化和师生矛盾过激 化。师生交往接触少、沟通减少。几乎所有的研究者都认 同目前师生交往存在接触少、沟通少的问题。主要表现为: 师生比例增大, 客观导致师生交往减少。高校后勤社会化, 使师生联系、交往更加困难。随着改革的进程, 学生宿舍逐 步脱离学校管理, 而教师也将散居于校外各地。这一分散 趋势加上交通工具的制约和学校硬件的不足, 使师生的联 系交往和讨论交流变得更为不便和困难。师生关系存在功 利倾向。高校教育产业化的推行改变了部分学生对教师的 认识, 师生之间缺少产生更深层次感情的基础。教育被部 分人等同于了商业服务, 师生关系被结定为服务与被服务 的关系。就大学生而言, 有些人存在着诸如拜金主义、自 由主义、个人主义等一些不健康的东西, 功利色彩非常浓 厚。就老师而言, 有些教师受不良社会风气影响, 把交往 变为交易, 给师生关系轻易也染上了铜臭味。于是出现了 教师兼职、教师从商、教师不将主要精力放在教学和科研 上等现象, 春蚕和蜡炬的无私奉献精神似乎离人们越来越 远, 教师的人格威信也不如以前。师生感情淡漠化。现在
的高校里, 师生间仅仅是一种冷冰冰的知识传授过程。教 师上课来, 下课即走, 课堂上教师缺乏激情, 学生麻木漠 然。老师和学生都有怨气, 老师抱怨学生学习不努力, 不 懂得尊重老师; 学生则抱怨老师讲课不认真, 授课水平不 高, 不关心学生, 或是对学生要求过严, 不够宽容。由此 可见, 高校师生关系呈现淡漠疏远状态。师生矛盾过激化。 随着教育产业化的推行, 以及教育学界和社会與论对权威 高压型师生关系的批判, 高校里的师生关系走上了 “民主 化” 的道路, 而新问题也随之出现。部分高校学生随意逃 课, 考试作弊, 不尊重教师, 不遵守学校纪律等。而近年 来, 一些校园师生惨案事件层出不穷, 仅 2008 年 10 月份 一个月内全国就有三起学生杀老师的事件见报。这些鲜明 的悲剧说明高校师生关系存在矛盾, 而且矛盾还有激化的 趋势。

\section{3. 研究生与导师沟通研究现状分析}

\section{1 国外研究现状分析}

导师与研究生的沟通是体现学生满意度的因素之一 (Powers, Rossman, 1985)。[1]有学者对美国社会心理学 系研究生的调查结果显示, 学生对研究生院的满意程度与 导师尊重学生程度成正相关 (Nadden, Carlie, 1983)。有 研究者 (KatZ, Hartnett, 1976) 通过研究发现研究生与其 导师的沟通可能是研究生部分中最为显著的一个特征, 导 师的易获得性及导师对研究生的态度反应出了师生之间的 心理距离, 以及研究生所感知的被导师接受和尊重的程度。 但是导师与研究生之间的沟通还不尽如人意。[2]但沟通次 数少与研究生对师生沟通评价并无显著相关, 有些研究生 表示, 虽然自己和导师沟通次数少, 但沟通质量却很高 （Heiss，1967）。[3] 甚至有研究生表示, 希望能够免受权 威思想的影响, 以保持独立, 他们认为导师不应该充当满 足个人需要的看管者, 应该是能提供及时、准确的信息的 传播者( (Fie1stein, 1987)。[4]Gallois 和 Callan 利用 沟通适应理论 (CAT) 对研究生与导师的沟通进行了研究, 对 31 对导师一研究生进行了访谈, 结果发现影响师生沟通的 因素包括控制力、地位、指导、学术身份、研究生的独立 性和面子。[5]一项关于加利福尼亚大学 6 个系师生沟通的 研究将导师们分为 “强沟通” 群、“中沟通” 群和 “弱沟 通” 群。强沟通群导师与个人风格有关, 他们与学生之间 的沟通更开放, 接触更灵活。与学生的谈话并不局限于学 科, 也帮助学生处理个人生活上的一些问题 (snow, 1973)。 [6]师生沟通存在着显著的学科差异, 社会科学专业的导师 认为在课外与学生间的沟通更有价值, 并且在 “最近一 周” 和导师进行沟通的社会科学研究生人数是自然科学专 业研究生的三倍。[7] 


\section{2 国内研究现状分析}

有研究者对赴美读研的学生进行访谈时, 发现在读书 期间与导师的沟通十分必要, 甚至已经关乎研究生是否能 够顺利毕业。[8]在国内, 由于某些导师无暇顾及学生、带 研究生过多、不大关心学生发展、给学生增加负担等导致 师生极少沟通 (陈世海、宋辉, 2003)。[9] 另外, 大多数研 究生表示与导师交流不足, 并希望导师能够改变过于严肃 的态度主动和学生多交流。[10]有个别学校意识到这个问 题, 尝试一种新的研究生培养模式一导师组培养, 以消除 师生沟通不足的状况。[11] 针对师生沟通状况中存在的一 些问题, 北京理工大学冯长根教授根据自己的丰富经验和 亲身经历, 给研究生提了六条关于如何和导师相处的建议: 保持联系; 让导师得到你的消息; 摸清导师脾气; 赢得导师 的尊重; 稍稍有些个性; 为导师写一点东西。 ${ }^{[12]}$ 尊重导师、 按照导师制定的培养计划严格要求自己、带着问题去请教 导师、定期向导师汇报学习状况和研究成果同样对于师生 有效沟通有着重要的作用。[13] 在和导师沟通之前做好相 应的准备, 以保证沟通时言简意赅, 节约时间。而同时作 为研究生导师也应该扮演好自己的角色并承担相应的责 任, 包括提供专业指导、科研训练、积极地提问和批判、 督促和激励、示范科学精神和态度、提供学业支持。 [14] 龚怡祖等在 “主体间性” 视域下对高校师生之间的沟通进 行了解读, 并认为 “主体间交往是现代师生沟通的实践取 向”, 将 “工具沟通姿态升华为心灵沟通姿态, 由片面的 知识传授扩一展为完整的 “生活世界”。[15]但是, 由于 师生交往过程中地位的不平等性、交往主体观点的片面性 等导致了目前高校师生交往的 “虚假化”。因此建议高校 教师应该本着对话、理解、欣赏的态度和进行师生交往。 [16]

\section{4. 对师生关系改善的建议}

\section{1 对学生的建议}

中学生要积极完成老师的作业, 及时的与老师进行沟 通, 大学生首先尊敬老师, 自己喜欢的专业方向的老师多 进行沟通, 确定好以后的方向, 研究生选择适合自己的导 师、增强独立性、主动和导师沟通、主动提高自己的学术 水平、制定明确的规划。

\section{2 对老师的建议}

老师应该做到以下几点: 先为人师、提高对硕士研究 生的了解程度、要用 “心”、相信学生、和学生保持适当 的距离。

学生和老师都做好自己应尽的责任和义务, 建立好的 师生关系就不是难题了。

\section{Acknowledgment}

This study was supported by Inner mongolia normal university graduate students' research \& Innovation fund (NO. CXJJSZD13005) and Inner Mongolia Autonomous Region graduate education innovation project.

\section{参考文献(References)}

[1] Powers, S., Rossman, M.H.student satisfaction with graduate edueation: Dimensionality and assessment in a college edueation. Psychology: A Quarterly Journal of Hunlan Behavior.1985, 22:46-49.

[2] Katz, J., Hartnett, R.Scholars in the making: The development of graduate and Professional students. Cambridge, MA: Balinger.1976.

[3] Heiss, A.M.Berkeley doctoral students apraise their aeademic progams. Educational Rceord.1967:30-40.

[4] Fielstein, L.L.Student preferences for personal contacts in student-faculty advising relationship, 1987.

[5] Willemyns, M.T., Gallois, C.and Callan, v, "An interpretive analysis of postgraduate student-advisor Conversatlons: An intergroup approach Paper Presented at the annual meeting of the International Conmmunieation Assoeiation, New Orleans Sheraton, New Orleans. 2004(5):27

[6] Snow, S.G., Correlates of faculty-student interaction. Sociology of Edueation. 1973, 489-498.

[7] Gamson, Z.F.Performance and personalism in student-faculty relations, In Feldman, K.A.(Eds), College and student: Selected Reading in the Social Psychology of Higher Edueation. New YOrk: Pergamon. 1972.

[8] Liuyu.Importance of Communication with Tutors. The Twenty-First Century, 2005:40-41.

[9] Chenshihai, Songhui, et al. The relationship between tutors and graduate research -- in a central China University as a case. Youth Studies, 2003(6):27-30.

[10] Xuhuilin, Zhuangiianlin, et al. Analyzes the relationship between Medical postgraduate research students and teachers. China Higher Medical Education, 2007(6):3-4.

[11] Pengguohua, Ganyongtao. Give full play to the role of supervisor group to improve the quality of graduate students to the questionnaire survey and analysis of the relationship between teachers and students in the education of graduate students. Jilin Education Science, 2003(1):79-82.

[12] Agui. Study six advice students and supervisors..Way of Success, 2008:5.

[13] NetEase blog. Graduate students should learn how to communicate with teachers http:// edu.163.coln/1020-28/ 14zsu4EFloso0293oMZ.htm-20103.10.

[14] Zhouqiaolin, Liufeng. Construction of doctoral supervisor's role and responsibility--conceptual framework. Academic Degrees \& Graduate Education, 2008(9):26-29.

[15] Gongyizu, Zhuyuanyuan."I-you": "the world university teacher-student communication oriented view of inter subjectivity". Higher Education Exploration, 2009(3):114-118.

[16] Zhangjianming. False: Alienation of Communication Association of university teachers and students. Forum on Contemporary Education, 2007(7)41-43. 